\title{
Evaluación físico química de la calidad de agua en los Esteros Ribereños de San Bernardo y Pedregal, Golfo de Fonseca, Honduras 2005 al 2010
}

Fátima Griselda Gutiérrez *,German Guandique **, Liliam Carina Marroquín **

\section{RESUMEN}

La calidad del agua es fundamental en cualquier proceso, ya que de ella dependerá que el desarrollo de los organismos sea favorable, así como los rendimientos que se pretendan obtener. Los Esteros San Bernardo y Pedregal, están relacionadas con la industria camaronera, por ser la fuente principal de agua en la producción de casi el $40 \%$ del camarón nacional.

Los análisis se realizaron con la base de datos del Laboratorio de Patología Acuática y Calidad de Agua "Dr. Gabino Zúniga E. Arias", del periodo 2005 al 2010, siendo los parámetros evaluados: alcalinidad, nitrógeno total, fósforo total, demanda bioquímica de oxígeno (DBO-5), salinidad y sólidos sedimentables. Se demostró que los cambios a lo largo del tiempo en estos esteros no ha sido de impacto sobre la calidad del agua, lo que nos indica que las prácticas acuícolas de la zona están en armonía con el medio ambiente.

Palabras Clave: calidad de agua, alcalinidad, nitrógeno total, fósforo total, demanda bioquímica de oxígeno (DBO-5), salinidad y sólidos sedimentables.

\section{ABSTRACT}

Water quality is essential in any process; from it will depend the positive development of organisms and the expected results. The Estuaries, San Bernardo and Pedregal, are related to the shrimp industry, for being the main source of wáter in the production of $40 \%$ of the nation's shrimp.

The analysis were performed using the data base of the Aquatic Pathology and Water Quality Laboratory named after Dr. Gabino E. Zuniga Arias. During the period from 2005 to 2010, the following parameters were evaluated: alkalinity, total

Universidad Nacional Autónoma de Honduras. Centro Universitario Regional del Litoral Pacífico. Departamento de Agroindustria. Carrera de Ingeniería Agroindustrial.

Universidad Nacional Autónoma de Honduras. Centro Universitario Regional del Litoral Pacífico. Departamento de Agroindustria. Carrera de Ingeniería Agroindustrial. Asesor. adolfo_66@yahoo.es: Asesora.carimarroquin@yahoo.es 
nitrogen, total phosphorus, biochemical oxygen demand (BOD-5), salinity and settleable solids, demostrating that over time the changes in these estuaries have not impacted on water quality. This indicates that aquaculture practices in the area have been in harmony with the environment.

Keywords: water quality, alkalinity, total nitrogen, total phosphorus, Biochemical Oxygen Demand (BOD-5), salinity and Settleable Solids, abastract 


\section{INTRODUCCIÓN}

La calidad del agua está determinada por la hidrología, la fisicoquímica y la biología de la masa de agua. Las características hidrológicas son importantes ya que indican el origen, cantidad del agua y el tiempo de permanencia, entre otros datos. Estas condiciones tienen relevancia ya que, según los tipos de substratos por los que viaja el agua, ésta se cargará de unas sales u otras en función de la composición y la solubilidad de los materiales de dicho substrato. Así, las aguas que discurren por zonas calizas (rocas muy solubles) se cargarán fácilmente de carbonatos, y en el otro extremo, los cursos de agua que discurren sobre substratos cristalinos, como los granitos, se cargarán muy poco de sales, y aparecerá en cantidad apreciable el sílice; estas sustancias pueden limitar, de modo igualmente natural, el tipo de usos del agua. Las aguas híper salinas o muy sulfurosas, por ejemplo, no se pueden usar como agua potable o de riego.

La temperatura tiene alto impacto en los procesos químicos y biológicos. Los procesos biológicos como crecimiento y respiración se duplican, en general, por cada $10{ }^{\circ} \mathrm{C}$ que aumenta. Los procesos de putrefacción y algunas reacciones químicas de degradación de residuos potencialmente tóxicos se pueden ver acelerados por el aumento de la temperatura.

Los camarones son criaturas delicadas, susceptibles de sufrir estrés ante condiciones ambientales adversas. En condiciones de estrés no comen bien y tienden a enfermarse. Al mantener condiciones ambientales adecuadas en los estanques, los granjeros pueden incrementar la supervivencia, la conversión alimenticia y la producción de su cultivo.

Los factores que más afectan al camarón son las variables de calidad de suelo y agua. Los efluentes de las granjas pueden causar efectos adversos en las aguas con el incremento de nutrientes, materia orgánica y sólidos suspendidos. No obstante, el efecto negativo de los efluentes es menor si las granjas son adecuadamente manejadas, y si se mantienen buenas condiciones en la calidad de suelo y agua.

Las prácticas acuícolas van degradando el medio ambiente, por las grandes cantidades de desechos que recibe, como el alimento no consumido por los animales acuáticos, el cual se sedimenta en el fondo, además, de la introducción de antibióticos y sustancias químicas al ecosistema. 
Uno de los problema frecuentes es la eutrofización. Seda cuando las aguas se enriquecen en nutrientes originando un desequilibrio en la flora y la fauna, debido a la sobre población de algas y bacterias lo cual incrementa la competitividad del oxígeno en el agua, después que mueren, se pudren y llenan el agua de malos olores y le dan un aspecto nauseabundo disminuyendo drásticamente su calidad. Así también, la temporada de lluvias genera una acumulación de materias orgánicas y nutrientes, y éste puede ocasionar un incremento significativo en las poblaciones de cianofitas, bacterias y hongos causantes del mal sabor en el camarón de cultivo.

La importancia de la calidad del agua es un factor fundamental en cualquier proceso acuícola, ya que de ella dependerá que el desarrollo de los organismos sea óptimo en los tres niveles básicos: el crecimiento, la reproducción y la supervivencia.

\section{METODOLOGÍA}

\section{Diseño}

Los aspectos que se tomarán para esta investigación son la descripción y el análisis en sus distintas partes y cualidades. Asimismo, la comparación se hará al diferenciar los parámetros físicos químicos y por supuesto la retrospectiva, ya que es un estudio a través del tiempo; para determinar en qué afecta a la calidad de agua.

\section{Población y Entorno}

Se estudiaron dos esteros donde es mayor el desarrollo de la camaricultura de Honduras durante los años del 2005 -2010. El Pedregal con una humedad relativa $68{ }^{\circ} \mathrm{C}$ y una latitud de 13.02 y el Estero San Bernardo con una humedad relativa de $72{ }^{\circ} \mathrm{C}$ y una latitud de 13.1 , ubicados en Choluteca. Los análisis físico químicos se realizaron en el Laboratorio de Patología Acuática y Calidad de Agua Dr. Gabino Zuniga E. Arias, Oficina Regional SENASA en la ciudad de Choluteca, ubicada en la zona sur de Honduras.

\section{Intervenciones}

Los análisis realizados a los esteros fueron en base en los siguientes parámetros: alcalinidad, nitrógeno total, fósforo total, demanda bioquímica de oxígeno (DBO-5), salinidad y sólidos sedimentables; conforme al estándar del método para la examinación de agua y agua de mar. 


\section{Recopilación de datos y variables evaluadas}

Los datos fueron recopilados de los documentos de registro del Laboratorio de Patología Acuática y Calidad de Agua (LPACA) para los parámetros físico químicos de alcalinidad, nitrógeno total, fósforo total, demanda bioquímica de oxígeno (DBO5), salinidad y sólidos sedimentables de los esteros Ribereños San Bernardo y Pedregal, a partir de enero del 2005 hasta diciembre del 2010.

\section{Análisis estadístico}

Se realizaron comparación de medidas a lo largo de cinco años, en época lluviosa y seca, revisando en cada uno de los parámetros para observar las variaciones y su evolución conforme al tiempo.

\section{RESULTADOSYDISCUSIÓN}

\section{Salinidad}

La salinidad en época seca siempre se mantiene en concentraciones altas, tanto en el Estero San Bernardo como en el Estero Pedregal. Esto se da porque los iones se concentran a causa de la evaporación, y el poco recambio de agua que hay por la marea. Cuando hay altas concentraciones de salinidades en época lluviosa eso es un indicativo que en ese año no llovió suficiente o fue un invierno corto, como ocurrió en el año 2009.

\section{Alcalinidad}

La habilidad de amortiguación que mide la concentración de carbonatos y bicarbonatos en el agua. Estas substancias al mezclarse con los ácidos del agua hacen que estos sean menos fuertes, indicándonos el rango permisible sin afectar la vida de los animales acuáticos.

\section{Nitrógeno total}

Las concentraciones de nitrógeno se mantienen en las dos épocas a diferencia del año 2009 , el cual posiblemente hubo mucha lluvia y haya sido un verano corto.

\section{Fósforo total}

En los últimos tres años $(2008,2009$ y 2010) este parámetro se incrementó en 
comparación a los otros años anteriores. Toda esta cantidad de fósforo cumple un ciclo, siendo principalmente removido del agua por el fitoplancton y las bacterias. Además cierta parte del mismo queda atrapado dentro del estanque, especialmente en el fondo en los sedimentos.

\section{Demanda bioquímica de oxígeno (DBO-5)}

La cantidad de oxígeno consumida por los cuerpos reductores presentes en el agua sin intervención de organismos vivos que hubo en el agua se han mantenido. Este parámetro no afectó la calidad del agua durante los cinco años evaluados.

\section{Sólidos sedimentables}

Este parámetro también se ha mantenido a lo largo de los años el cual no representa variación alguna. Esto se debe a su ubicación cerca de la boca del mar y al buen recambio de agua.

\section{CONCLUSIONES}

Los parámetros evaluados nos indican que en el periodo analizado las concentraciones se mantienen, debido a que el Estero San Bernardo y el Estero Pedregal tienen influencia de río y conservan buenas concentraciones de nutrientes. Por su ubicación en la boca del mar tienen buen recambio de agua.

A pesar de la explotación por parte de las camaroneras, los parámetros han permanecido estables y dentro de los rangos permisibles, por lo que vemos que las prácticas por parte de las camaroneras no han contaminado el ambiente acuático.

En los años 2008-2010, incrementó la cantidad de fósforo total, pero ésto no perjudicó de ninguna forma, ya que los niveles de fósforo aumentaron de $0.25 \mathrm{mg} / \mathrm{la}$ $0.50 \mathrm{mg} / \mathrm{l}$. El límite permisible es de $5 \mathrm{mg} / \mathrm{l}$, según las normas técnicas de las descargas de aguas residuales a cuerpos receptores y alcantarillado sanitario, acuerdo No. 058 del 9 de abril del 1996, vigente desde 13 de diciembre.

\section{AGRADECIMIENTOS}

Agradezco al Laboratorio de Patología Acuática y Calidad de Agua Dr. Gabino Zúniga E. Arias, por las facilidades brindadas para realizar el proyecto "Evaluación físico química de la calidad de agua en los Esteros Ribereños de San Bernardo y Pedregal" 


\section{BIBLIOGRAFÍA}

- APHA .1992. Standard method for the examination of water and waste water, 18th edition. American Public Health Association, Washington, DC.

- APHA.1995. Standards methods for the examination of water and waste water, 19 th edition. American Public Health Association. Washington DC.

- Grasshoff. K. M. Ehrhardt K. Kremling. 1983 Methods of SeawaterAnalysis.

- Parsons, T.R y Lalli, C. M., 1984. a manual of chemical and biological methods for seawater analyses. Pergamon Press.

- APHA.1995. Standards methods for the examination of water and waste water, 19 th edition. American Public Health Association. Washington DC.

- Sawyer,C.N. \& L.Bradney.1946, Modernization of the BOD test for determining the efficiency of the sewage treatment process. Sewage Works J. 18:1113. 